\title{
A study on the comparison of dynamic behaviour of high speed railway bridges
}

\author{
S. I. Kim, H. M. Kim \& I. H. Yeo \\ Department of Track \& Civil Engineering, \\ Korea Railroad Research Institute, Korea
}

\begin{abstract}
The dynamic behaviour of two steel bridges crossed by the Korean High Speed Train (KTX) has been investigated experimentally and the results are compared with the specification requirement and other typical prestressed concrete box girder bridge's responses. The investigated bridges are 2-girder steel bridges of 1@40m span length, 2@50m span length, and a PSC Box girder bridge of $2 @ 40 \mathrm{~m}$ span length. A set of experimental tests were performed during the operation of KTX, and a number of accelerometers, LVDTs and ring-type displacement transducers were utilized for measurement of three kinds of dynamic responses (acceleration, deflection, and end-rotation angle). The measured responses show that the vertical deflections and end-rotation angles of the three bridges all satisfy the specification requirement with a large margin, but acceleration responses that are very close or exceed the limit value were also found. Most of the excessive acceleration responses were found when the passing speed of the train is close to the critical velocity, which causes resonance. No noticeable differences of dynamic responses due to the different materials (steel or concrete) could be found within these experimental results.
\end{abstract}

Keywords: high speed railway bridge, bridge-train interaction, moving load.

\section{Introduction}

A high speed railway bridge must support trains travelling at speeds of up to 350 $\mathrm{km} / \mathrm{h}$. The possibility of resonance occurring due to the cyclic dynamic load is extremely high. For this reason, safety evaluation and dynamic movement evaluation are both critical elements in the development of a high speed railway bridge. 
Most of the bridges along Korea's Gyeong-bu High Speed Railway consist of 2-span continuous PSC box girder bridges, with each span at a length of 40 meters. In parts where the railway passes through the city or roads, the bridges are mostly 2-girder steel plate girder bridges with $40 \mathrm{~m}$ to $50 \mathrm{~m}$ spans. In some parts, arch bridges have been set up. PSC box girder bridges are dominant because there is a general consensus that concrete bridges are better than steel bridges in terms of vibration and noise. Both theoretical and experimental studies have been continuously done on the 2-span continuous PSC box girder bridges, which account for the majority of the bridges along the Gyeong-bu High Speed Railway. Recently, research has also been underway into approaches to reducing excessive vibration [1].

At the same time, research on the dynamic behaviour of the bridge caused by the moving train load has been pursued since the 1960s. In the study of railway bridges, the emphasis on this type of research has been increasing because of the possibility of resonance caused by the cyclic load of the train (Yang et al. [2]). Resonances occur in bridges when the exciting frequency of the train is equal to the natural frequency of the bridge. This resonance is directly related to instability in dynamic behaviour, and can have a very bad influence on the ride comfort of the train passengers (Sogabe et al. [3]). However, thus far there has been little research on the behaviour of actual high speed rail bridges while a train is moving along the bridge. Furthermore, there have as of yet been no research results presented comparing the dynamic behaviour of concrete and steel high speed railway bridges.

In this paper, we performed field experiments on the dynamic characteristics and behaviour of Ewon Bridge and Jitan Bridge. Both bridges are 2-girder steel composite bridges on Gyeong-bu High Speed Railway. We then compared the results of our experiments with the behaviour of Yeonjae Bridge, a PSC box girder bridge. We also compared the results with the standard dynamic behaviour requirements set forth by Eurocode and Korean High Speed Railway. Through interpretative analysis, we quantitatively compared the steel bridge to the PSC box girder bridge.

\section{Bridges}

We used three bridges as the subjects of this research. The first bridge was the $40 \mathrm{~m}$ simple span bridge between the $59^{\text {th }}$ pier and the abutment of Ewon Bridge. This bridge is located at the $174 \mathrm{~km}$ mark of Gyeong-bu High Speed Railway's Daejon - Gimcheon line. The second bridge is the Jitan Bridge (2@50m), which is located on the $177 \mathrm{~km}$ mark of the same railway line. The bridges are both 2girder steel composite bridges, and are shown in fig. 1. Girder depth is $3 \mathrm{~m}$ for Ewon Bridge, and $4 \mathrm{~m}$ for Jitan Bridge; distance between girders is $6.5 \mathrm{~m}$, and total bridge width is $14.0 \mathrm{~m}$. We chose Yeonjae Bridge as our comparison bridge. This bridge is a PSC box girder bridge with 2@40 m span, and is like the majority of the bridges on the Gyeong-bu High Speed Railway. 


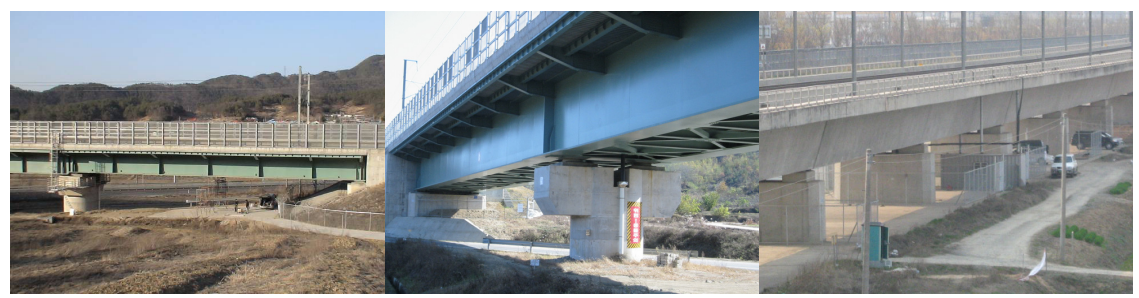

Figure 1: $\quad$ Ewon Bridge, Jitan Bridge and Yeonjae Bridge.

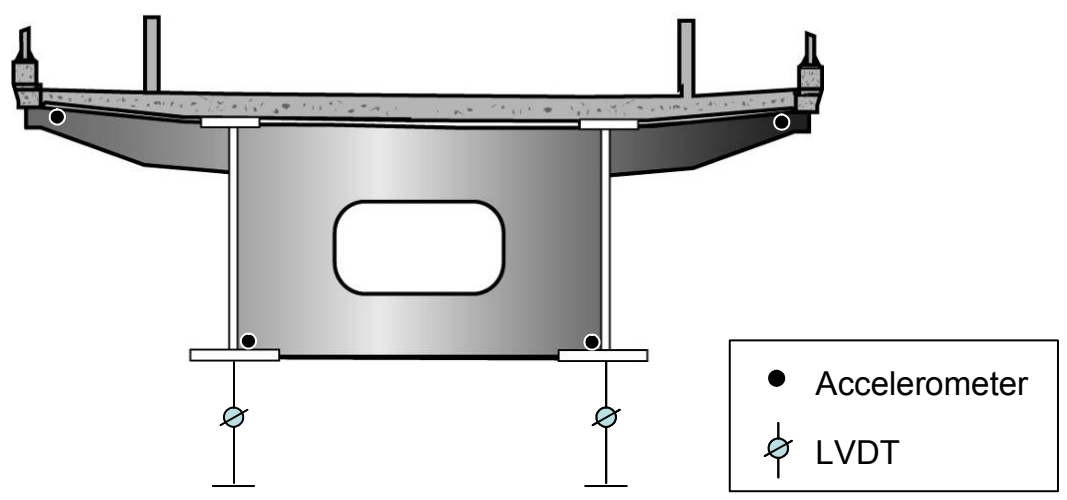

(a) $\mathrm{L} / 2$ section view

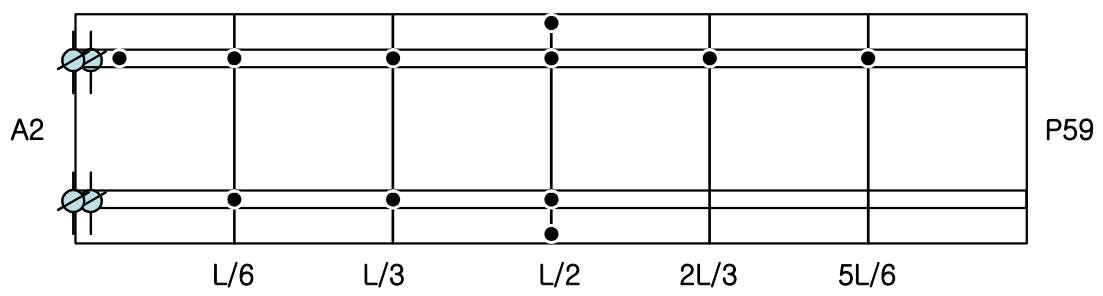

(b) Plan view

Figure 2: $\quad$ Sensor disposition map (Ewon Bridge).

\section{On-site experiments}

\subsection{Selection of measurement categories and placement of sensors}

Eurocode [4] and the specification of Korean High Speed Railway [5] used to evaluate the traffic safety and ride comfort criteria. Vertical deflection and vertical acceleration of the bridge deck are two major criteria.

To determine whether the dynamic performances of our test bridges satisfied the requirements of the standard, we measured the acceleration and displacement at the centre of the span, and also measured the rotation angle of the end deck. To obtain the rotation angle, we used two displacement sensors (LVDT or ring 
type sensors) placed at a constant distance from each other, and first obtained two vertical displacements. Then, we calculated the rotation angle from those measurements. In addition, we placed vertical direction accelerometers at constant intervals to measure specific dynamic characteristics (natural frequency, mode shape, damping ratio). The sensors used and their placements are shown in table 1 and fig. 2.

\subsection{Measurement of dynamic response}

Measurements of dynamic response on our subject bridges are performed on three separate dates. We used the previously-installed sensors and DAQ, and measured dynamic responses while a train passed over our subject bridges. Measurement data for each bridge is shown in table 2.

\subsubsection{Time domain data}

Figs. 3-5 below show examples of the data obtained from each bridge. In terms of the rotation angles of the end decks, we have shown the value calculated from the two measurements that we obtained from displacement sensors. The $\mathrm{S} / \mathrm{N}$ characteristic is relatively low in comparison to other measurements. However, we have concluded that it will not pose as much of a problem in investigating the overall dynamic behaviour characteristic of the bridge.

The sampling rate and the low-pass filter were set to $1000 \mathrm{~Hz}$ and $200 \mathrm{~Hz}$, respectively, to maintain consistency with our previous research.

Table 1: $\quad$ List of the installed sensors (Ewon Bridge).

\begin{tabular}{|c|c|c|c|}
\hline Sensor type & Q'ty & Location & Response \\
\hline accelero- meter & 11 & $\mathrm{~A} 2, \mathrm{~L} / 6, \mathrm{~L} / 3, \mathrm{~L} / 2,2 \mathrm{~L} / 3,5 \mathrm{~L} / 6$ & $\begin{array}{c}\text { natural frq. } \\
\text { mode-shape } \\
\text { acceleration }\end{array}$ \\
\hline $\begin{array}{c}\text { displacement transducer } \\
\text { (LVDT) }\end{array}$ & 2 & $\mathrm{~L} / 2$ & vertical deflection \\
\cline { 2 - 4 } & 4 & $\mathrm{~A} 2$ & end-rotation \\
\hline
\end{tabular}

Table 2: Quantity of the measured data set.

\begin{tabular}{|c|c|c|c|}
\hline \multirow{2}{*}{ Bridge Name } & \multirow{2}{*}{ Date } & \multicolumn{2}{|c|}{ Quantity of Data Set } \\
\cline { 3 - 4 } & & North Bound & South Bound \\
\hline Ewon & 2007.2 .27 & 14 & 13 \\
\hline Jitan & 2007.4 .13 & 5 & 5 \\
\hline Yeonjae & 2007.4 .11 & 22 & 20 \\
\hline
\end{tabular}



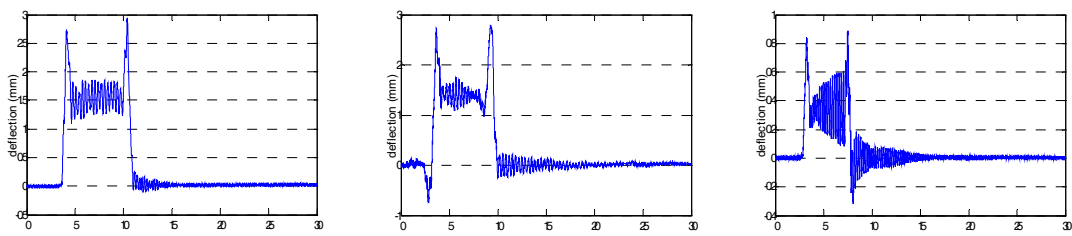

(a) Ewon $(v=221.6 \mathrm{~km} / \mathrm{h})(\mathrm{b}) \operatorname{Jitan}(\mathrm{v}=219.2 \mathrm{~km} / \mathrm{h})(\mathrm{c})$ Yeonjae $(\mathrm{v}=289.3 \mathrm{~km} / \mathrm{h})$

Figure 3: $\quad$ Vertical displacement of mid-span section.
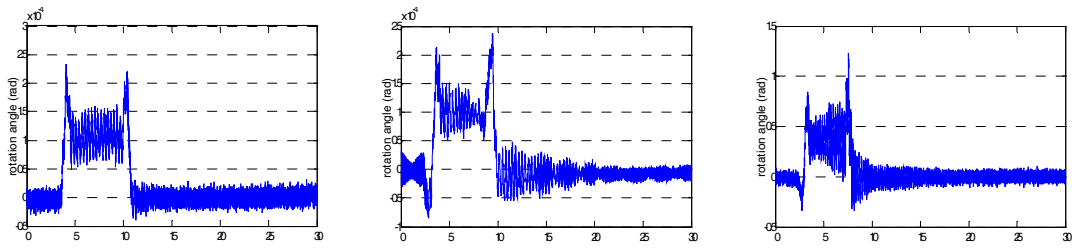

(a) Ewon $(v=221.6 \mathrm{~km} / \mathrm{h})$

(b) Jitan $(v=219.2 \mathrm{~km} / \mathrm{h})(\mathrm{c}) \operatorname{Yeonjae}(v=289.3 \mathrm{~km} / \mathrm{h})$

Figure 4: $\quad$ End-rotation angle.
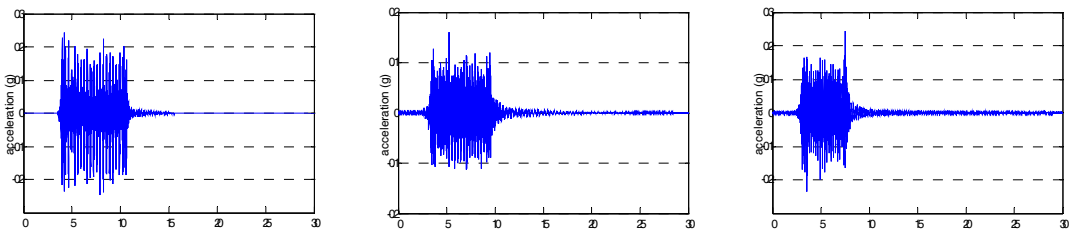

(a) Ewon $(v=221.6 \mathrm{~km} / \mathrm{h})(\mathrm{b}) \operatorname{Jitan}(\mathrm{v}=219.2 \mathrm{~km} / \mathrm{h})(\mathrm{c})$ Yeonjae $(\mathrm{v}=289.3 \mathrm{~km} / \mathrm{h})$

Figure 5: Vertical acceleration of mid-span section.

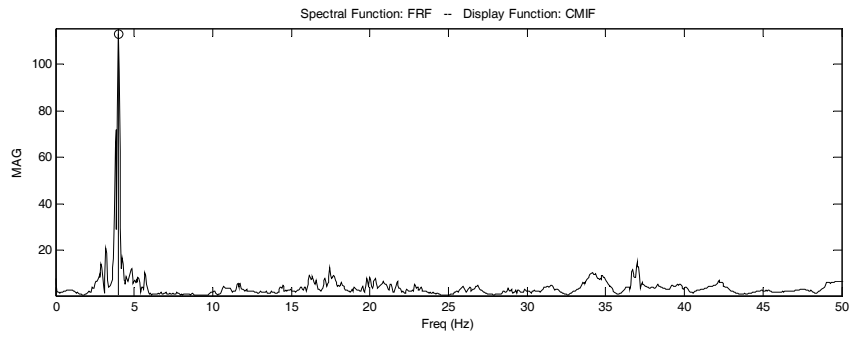

Figure 6: Acceleration spectrum of Ewon Bridge.

\subsubsection{Natural frequency, mode shape and damping ratio}

When the train is passing on the bridge, it is difficult to measure the natural frequency of the bridge independently, because of the interaction between the train and the bridge and the extra load of the train. Consequently, of the total measured acceleration signal, we only took the part after the train had left the bridge, and then extracted the natural frequency and mode shape. 
Fig. 6 shows the signal spectrum obtained from the nine accelerometers installed on the lower girder parts of the Ewon Bridge. Fig. 7 shows the mode shape extracted from the spectrum. As can be seen from the image, there are almost no excitations in modes other than the $1^{\text {st }}$ mode because of the train movement. The $1^{\text {st }}$ natural frequency was $4.0 \mathrm{~Hz}$.

To calculate the damping ratio of the subject bridges, we first obtained the frequency domain from the FFT spectrum of the corresponding mode. Then, we performed a curve fitting by using SDOF theory, and applied the least squares method. The following eqn. (1) is the formula that we used to obtain the frequency response function of SDOF.

$$
\frac{A\left(\omega / \omega_{n}\right)^{2}}{\sqrt{\left\{1-\left(\frac{\omega}{\omega_{n}}\right)^{2}\right\}+\left\{2 \xi\left(\frac{\omega}{\omega_{n}}\right)\right\}^{2}}}
$$

Here, $\omega_{n}$ is the natural frequency, $\xi$ is the damping ratio, and $A$ is the proportional constant.

Fig. 8 shows the curve fitting results of the $1^{\text {st }}$ mode from Jitan Bridge. We determined that the natural frequency was $3.08 \mathrm{~Hz}$, and the damping ratio was $1.2 \%$.

Real Mode Number: 1 - Frequency: $4 \mathrm{~Hz}$

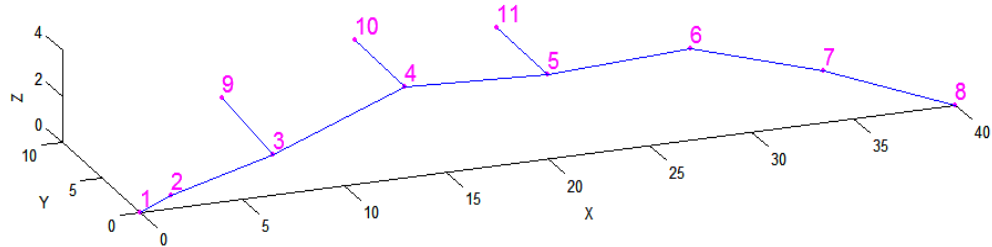

Figure 7: The $1^{\text {st }}$ vibration mode shape of Ewon Bridge.

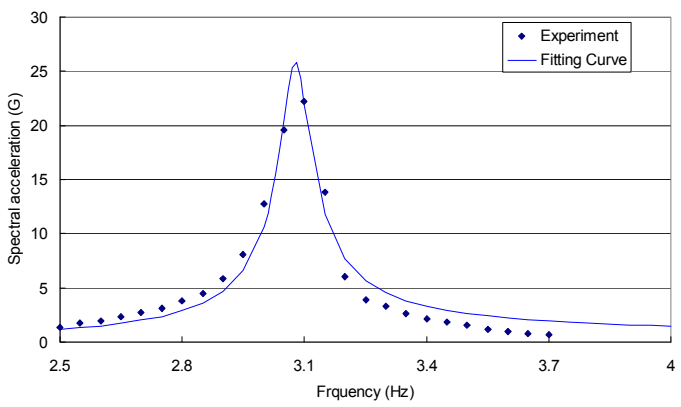

Figure 8: $\quad$ The $1^{\text {st }}$ mode curve fitting of Jitan Bridge. 
Table 3: Dynamic characteristics of the tested bridges.

\begin{tabular}{|c|c|c|c|}
\hline Bridge & $\begin{array}{c}\text { The } 1^{\text {st }} \text { Natural } \\
\text { frequency(Hz) }\end{array}$ & Damping Ratio(\%) & Critical Speed(km/h) \\
\hline Ewon & 4.0 & 2.4 & 269.3 \\
\hline Jitan & 3.08 & 1.2 & 207.3 \\
\hline Yeonjae & 4.35 & 2.4 & 292.8 \\
\hline
\end{tabular}

Table 4: $\quad$ Requirements of dynamic performances.

\begin{tabular}{|c|c|}
\hline Response & Reference Value \\
\hline Acceleration & $0.35 \mathrm{~g}$ \\
\hline $\begin{array}{c}\text { Vertical Deflection } \\
\text { (for Passenger Comfort) }\end{array}$ & $\mathrm{L} / 1900=21.05 \mathrm{~mm}($ for $\mathrm{L}=40 \mathrm{~m})$, \\
$\mathrm{L} / 2200=22.73 \mathrm{~mm}($ for $\mathrm{L}=50 \mathrm{~m})$, \\
\hline End-rotation & $5 \times 10^{-4} \mathrm{rad}$ \\
\hline
\end{tabular}

Table 3 shows the natural frequencies and the damping ratios of each bridge.

Bridge resonance caused by the train load occurs when the $1^{\text {st }}$ bending natural frequency of the bridge is equal to the frequency of the passing train, as shown in eqn. (2) below.

$$
\Omega(H z)=V / S_{\text {eff }}=\omega_{1}(H z)
$$

Here, $\Omega$ is the train's frequency, $\mathrm{V}$ is the train's velocity, $\mathrm{S}_{\mathrm{eff}}$ is the effective beating interval of the train, and $\omega_{1}$ is the $1^{\text {st }}$ natural frequency of the bridge.

Therefore, the critical speed of the train that causes the resonance can be expressed as in eqn. (3). If the natural frequency of the bridge and the effective beating interval of the train are known, then the critical speed can be estimated in advance. Unlike ordinary highway bridges, over which all types of vehicles pass at random intervals, only specific trains are allowed to pass over railway bridges. Consequently, we can analyze the critical speed that generates resonance by using eqn. (3). The natural frequency of the bridge, and $18.7 \mathrm{~m}$, the effective beating interval of the KTX, can be substituted into the formula to calculate the critical speeds. The calculated speeds are shown in table 3.

$$
V_{c r}=\omega_{1} \times S_{e f f}
$$

\section{Dynamic responses}

\subsection{Criteria for dynamic performance}

The evaluation standard for vertical deflection, vertical acceleration and rotation angle of the end deck are listed in Eurocode and in the design guideline for Korean High Speed Railway. All of these standards are shown in table 4. 


\subsection{Investigation of dynamic performance measurements}

\subsubsection{Maximum deflection}

In fig. 9, the maximum displacements obtained from the three bridges are shown in proportion to the standard value. The standard value in accordance with the standard set in table 4 is $21.05 \mathrm{~mm}$ for Ewon and Yeonjae Bridges, and 22.73 for Jitan Bridge.

As can be seen, the maximum deflection was greatest for Ewon, followed by Jitan and Yeonjae, respectively. All three bridges showed safe responsive values in comparison to standard values. When compared with the PSC box girder bridge, vertical displacements of steel bridges are great. However, the deflection is still within $15 \%$ of the standard, and is therefore sufficient.

\subsubsection{Maximum vertical acceleration}

Fig. 10 shows the measurements of the maximum vertical acceleration of the bridge deck.

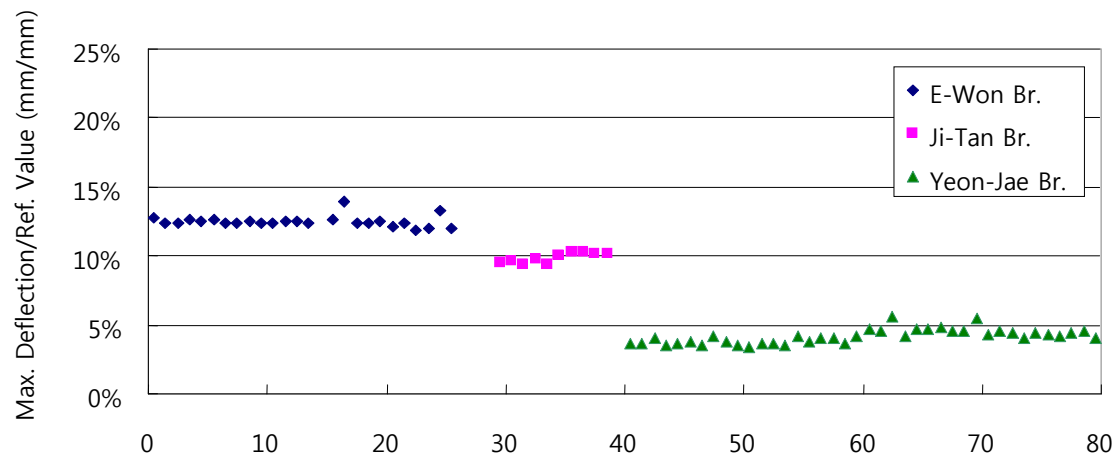

Figure 9: $\quad$ Measured maximum vertical deflections.

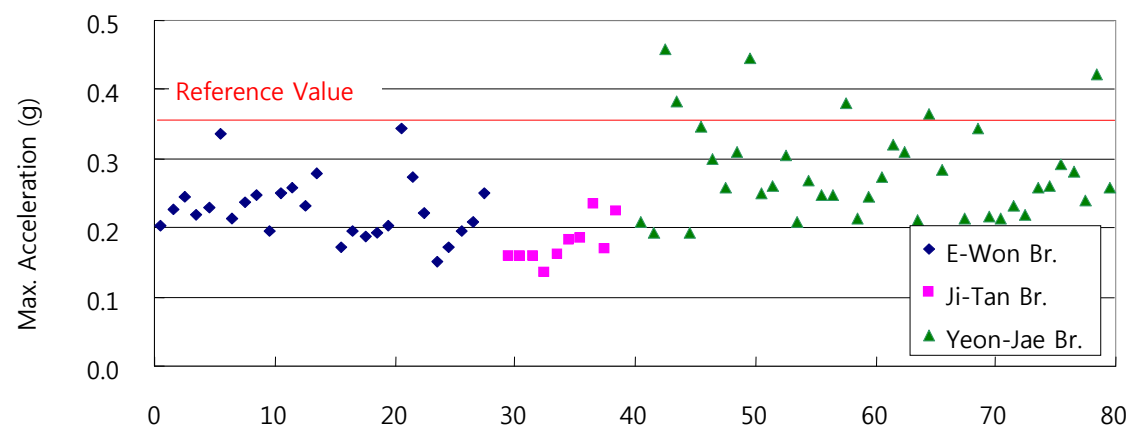

Figure 10: Measured maximum vertical accelerations. 
The results obtained in the measurement of vertical acceleration were very different from the vertical displacement results. In other words, responses exceeding the criteria were generated from the Yeonjae Bridge - the PSC box girder. This is because when the train is moving on Yeonjae Bridge, the actual train speed approaches the critical speed, and thus generates resonance. On Ewon Bridge, the acceleration response is relatively higher than that of Jitan, but no responses exceeding the standard were observed.

\subsubsection{Rotation angle of the end deck}

Fig. 11 shows the maximum values for the rotation angles. The angles closely resemble the results of the vertical deflections. However, in the case of Ewon Bridge, a greater angle was measured in the northbound lane than in the southbound lane. Yeonjae Bridge showed similar results. We concluded that the results are related to differences in passenger numbers and running characteristics between the two lanes. As in the case of the displacements, the greatest rotation angle was observed on Ewon Bridge, followed by Jitan and Yeonjae Bridges, respectively. All of the angles were within the criteria.

\subsection{The importance of actual running speed}

When a high speed railway bridge has a high likelihood of resonance when the train is operating at its normal speeds, then the train may cause the dynamic instability of the bridge when operating at critical speeds. The behaviour at this time is controlled by the damping ratio. Therefore, the actual running speed of the train is very important in relation to the dynamic characteristics of the bridge. Fig. 12 shows train speeds on the Yeonjae Bridge, a PSC box girder (2@40) and on the steel composite bridges Ewon (1@40) and Jitan Bridge (2@50).

As it can be seen in the figure, the actual running speed on the Yeonjae Bridge is very close to the critical speed, while for Ewon and Jitan Bridges, the running speed is quite far from the critical speed.

Fig. 3 shows the time history curve of vertical displacements on Yeonjae and Ewon Bridges. As can be seen in the figure, the curve of Yeonjae Bridge is

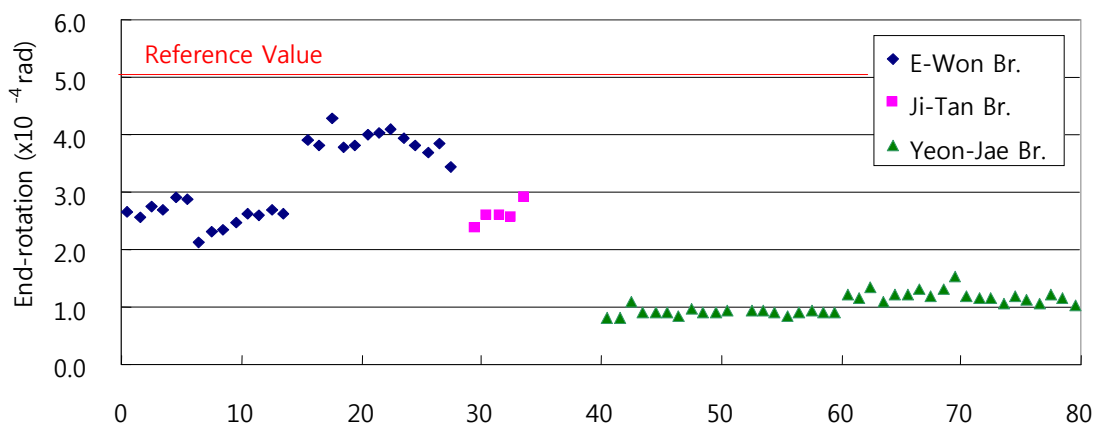

Figure 11: Measured maximum end-rotation angles. 


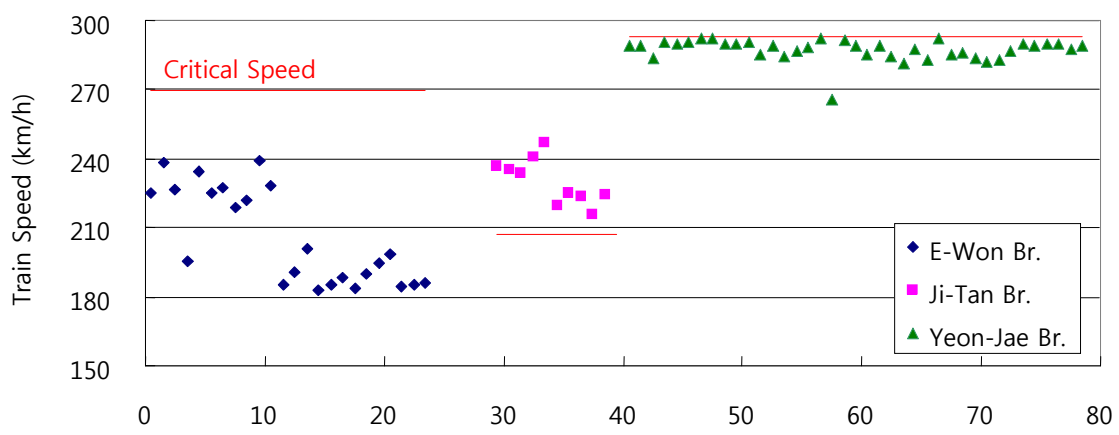

Figure 12: Critical speeds and train-passing speeds.

similar to that of a resonance wave, while for Ewon, the curve is a typical vertical displacement time history curve caused by the KTX.

All three bridges have sufficient surplus displacements. In the case of the Yeonjae Bridge, because of the high rigidity of the PSC box girder bridge, it has sufficient surplus displacement, even if resonance does occur. However, continuous resonance waves like those shown in fig. 3(c) can shorten bridge life. In addition, in the case of vertical acceleration, the Yeonjae Bridge is shown to have higher acceleration results than the steel composite bridges because of the generation of resonance.

Generally, steel composite girders are known to be more vulnerable to noise and vibration than concrete bridges. Our results, however, show that when the bridges have the same level of static/dynamic performance, what matters more than the form of the bridge are its dynamic characteristics. We also discovered that the actual running speed of the train can have a great influence on the bridge.

\section{Conclusion}

In this paper, we performed dynamic measurements on part of the Ewon Bridge, and on Jitan Bridge. Both are bridges along the Gyeong-bu High Speed Railway. We then compared the results with the dynamic performance standard values set forth by Eurocode and Korean High Speed Railway, as well as with response values from Yeonjae Bridge, a PSC box girder bridge.

To identify the dynamic performance of the bridges, we measured and analyzed the following elements: maximum vertical acceleration, maximum vertical displacement, and rotation angle of the end decks. Most of the measurements were within the regulation values. On Yeonjae Bridge, however, some acceleration responses exceeded regulation values.

The steel composite bridge showed higher values for displacement and rotation angles in comparison to the PSC box girder bridge. However, for acceleration response it showed lower values. This result shows that although the steel composite bridge is lower in rigidity than the PSC box girder bridge, there 
are lower acceleration responses, because no resonance occurs when the train passes through the bridge.

Therefore, the component that controls the dynamic performance of the bridge is whether or not resonance is generated. Differences in bridge material did not result in differences in the dynamic performance of the bridges.

The dynamic responses obtained and analyzed in this paper were all obtained when the train was running at an operating speed. Therefore, we are conducting further numerical analysis of the influence of resonance caused by changes in speed.

\section{Acknowledgement}

This research was supported by a grant from Railroad Technology Development Program (RTDP) funded by Ministry of Land, Transport and Maritime Affairs of Korean government.

\section{References}

[1] E.S. Choi, W.J. Chin, J.W. Lee, J.W. Kwark, J.Y. Kang, B.S. Kim, Diminution of bridge vibration for high-speed trains, Journal of the Korean Society for Railway, 9(1), pp. 125 130. 2006.

[2] Yang Y.B., Yau J. D. and Hsu L.C., Vibration of simple beams due to trains moving at high speeds, Engineering Structures, 19(11), 936-944, 1997.

[3] Sogabe, M., Matsumoto, N., Kanamori, M., Sato, M. \& Wakui, H., Impact factors of concrete girders coping with train speed-up", Quarterly Report of RTRI, 46(1), 46-52, 2005.

[4] EUROCODE 1 Pt. 2, Actions on Structures: General Actions - Traffic Loads on Bridges, European Committee for Standardization, 2003.

[5] Korea Rail Network Authority, Design Specification for Honam High Speed Railway, Korea Rail Network Authority (in Korean), 2007. 